\title{
Internet-based Collaborative E-Exercisebook System for Primary Math Teaching
}

\author{
M.J.C.S. Reis ${ }^{1}$, Miguel Bacelar ${ }^{2}$, Maria G.A.D. Reis ${ }^{3}$, Daniela Meira ${ }^{4}$, Maximino Bessa ${ }^{5}$, \\ Emanuel Peres ${ }^{2}$, Raul Morais ${ }^{6}$, António Valente ${ }^{1}$, Salviano Soares ${ }^{1}$, José Bulas-Cruz ${ }^{2}$ \\ ${ }^{1}$ IEETA, UTAD/ECT, Engineering Department, 5001-801 Vila Real, Portugal. E-mail: \{mcabral, avalente, salblues\}@utad.pt. \\ ${ }^{2}$ UTAD/ECT. Email: \{mbacelar, eperes, jcruz $@$ utad.pt. \\ ${ }^{3}$ Agrupamento Vertical de Escolas de Peso da Régua, Lugar das Alagoas, 5050-090 Godim, Email: mgentil.reis@gmail.com. \\ ${ }^{4}$ Escola S/3 S. Pedro, Rua Morgado Mateus, 5000-455 Vila Real. Email: danielameira@ gmail.com \\ ${ }^{5}$ INESC Porto, UTAD/ECT. E-mail: maxbessa@utad.pt. \\ ${ }^{6}$ CITAB, UTAD/ECT. E-mail: rmorais@utad.pt.
}

\begin{abstract}
The academic performance and social competence of a child in school is positively associated with the involvement of their parents. However, the researches about educational learning models often ignore the parents' part. Internet opens a new paradigm: education and communication approach is more complex than ever. Here, we would like to present an Internet based system to support students' homework. We believe that one of the major advantages of our system is time saving, particularly from the teacher's point of view. Also, this system gathers statistical data concerning different groups of students selected by the teacher. From these data on, the teacher can easily see where the students are having problems and decide what to do next. From the student (or parent) point of view, the prompt feedback about the exercises correctness, added to the training with different exercises sets about the same subject, besides the utilization of video, color, sound, etc., that positively reinforce child's senses, are elected as the main advantages.
\end{abstract}

\section{AIMS AND ORGANIZATION}

The "Mediappro" report (http://www.mediappro.org/, with the support of the European Commission/Safer Internet Action plan) let us know that due to the small number of computers in schools, the slow Internet connections and to the poor integration of IT in the curriculum, students 12-18 years old have a more frequent access to the Internet at home than at school. In the Portuguese case, $92.8 \%$ use the Internet; form these $42 \%$ use it at home in a daily basis, and only $5 \%$ use it daily at school.

As it will be explained in some detail in section II-A, the Portuguese computational park is very diverse, both scholar, personal, desktop and laptop computers, ranging from low-processing capabilities (e.g., computers running under a Pentium I microprocessor and lower) and low-memory (both main-RAM-memory and secondary-hard-drivememory) to high-processing capabilities and high-memory. Additionally, in some rural areas the Internet connections are limited to $128 \mathrm{Kbps}$ (Kilobits per second), but in urban areas Internet may reach $16 \mathrm{Mbsc}$ (Megabits per second) and more with ADSL (Asymmetric Digital Subscriber Line) connections and optical fiber. This is a consequence of the several different programmes being implemented during the last decades; see, for example, [1]-[3], and the governmental sites http://www.umic.pt/ and http://www.fccn.pt/.

Besides these difficulties, it was also elsewhere reported the need for specific teachers training and Internet contents (e.g., [4], [5]); in the Portuguese case the teachers also reported the lack of time to meet the program (curriculum) recommended by the Portuguese Ministry of Education.

With the Internet-based collaborative system presented in section III, we want to contribute to an increase in the resources available on the Internet for primary teaching of mathematics, and helping the creation of virtual communities through the provision and creation of groups of e-mails, forums, sharing of multimedia resources and georeferenced data. More specifically, we believe that this collaborative system may contribute to:

1) promote the use of IT by teachers and students;

2) promote teacher-student-parent communication;

3) stimulate the share of contents, activities and strategies, and thus allowing for a collaborative work through the Internet;

4) stimulate the interacting of the virtual teaching community;

5) contribute to the use of IT in more informal contexts;

6) freely extend the existent offer in Portuguese language;

7) contribute to the creation of a web-based platform that presents the programmatic contents in a playful form.

The paper is organized as follows. Section II is devoted to the presentation of the Portuguese scholar context, and also some literature review, with special attention to the case of mathematics. The collaborative system is presented in section III. Section IV is used to present a reflection about the system proposed here and some of its pedagogical strengths. The paper ends with the conclusions, section V.

\section{Contextualization}

\section{A. Portuguese context}

The Programme "Internet in the Schools", launched by the Portuguese Ministry of Science and Technology (MST) in 
1997, aiming at the development of Information Technology (IT) in the Portuguese schools. Each school (basic teaching, 2 nd cycle -5 th and 6 th grade, and secondary -7 th to 12 th) was provided with at least one multimedia computer linked to the Internet; a detailed account of how the educational system in Portugal and other countries are organized can be found in http://www.eurydice.org.

In 2006, the "ESchool" Programme (e.escola-http://www. eescola.net/indexA.aspx) enabled the purchase of laptops by students, form the 5th to 10th grade, and teachers for a price of $150 €$. More recently the Portuguese government has developed a set of protocols with Intel, the leading telecommunications operators (Optimus, TMN, Vodafone, and Zon), Microsoft, "Magic Box" (Caixa Mágica), and the local members, allowing children of the primary schools access portable computers "Magalean" (Magalhães), for a maximum cost of $50 €(\mathrm{http}: / / w w w . e e s c o l i n h a . g o v . p t / p o r t a l / s e r v e r$. pt/community/e-escolinha/200/apresentacao). Additionally, a huge effort is being done in equipping all the classrooms with interactive "blackboards".

Setting-up infrastructures is a relatively simple process in comparison with their actual usage, since both the necessary training and the change of habits that lead to routine usage are the result of slow and gradual processes; the need to train, motivate and involve the teachers, pupils and the community in general towards a correct use of IT tools entails a number of technical and cultural difficulties [4]-[9]. Additionally, several researchers claim that it is what teachers think and believe that ultimately shapes the activities in the classroom [10]-[12].

As noted by [13] "the primary school more so than ever has an important role in ensuring that as many pupils as possible are engaged in sustained, meaningful and equitable use of IT" and "teachers should strive for constructing meaningful and genuinely opportunities for children to use computers and, therefore, stimulating continued desire to use IT'.

\section{B. The need for Internet resources}

Computers are now a part of a child's natural environment [13]. Homes and schools have rapidly been transformed into sites of a globally connected multimedia culture, integrating a wide variety of audiovisual information and telecommunication tools and systems that students are expected to use, both in their interpersonal and educational environment. According to [14] people who are innovative and quick to adopt new technology are usually younger, better educated and come from higher socio-economic households. Recent studies suggest that there are no longer differences in the rates of Internet access between genders and that the divide between ethnic groups is decreasing, and that students from rural households may have less access to IT from home because of many different factors, ranging from economic issues to a lack of parental interest in technology; however, students whose parents had more prestigious occupations and higher level of education were more likely to have access to both a computer and the Internet at home [15]. A significant number of parents and teachers believe that computers are highly important for the education of young children and their later success, while those without computers at home and at school are often viewed as disadvantaged [16]. Children's early experiences with computers have long been argued to be crucial to the development of positive attitudes towards IT usage in later life [17].

On the other hand, greater Internet usage raises concerns about the possible negative effects on the children's social interaction [18]-[20], risks of exposure to pornography, dangerous strangers and other unsuitable material online [21], lack of sleep, increased obesity and consequences on children's homework interference [22], [23]. According to a survey conducted by the European Opinion Research Group EEIG [24] on the illegal and harmful content on the Internet, a fair share of European Union parents (32\%) seem not to be aware of the possible risks that their child may encounter on the Internet. It is not possible (or even desirable) for parents to be with their children constantly and the home is not the only point of access to IT.

Associated with this is the parents' strong belief that technological interactivity is an alternative form of human communication [25]. In practice, it appear that the technological interactivity with children can cause problems to parents as they seem not confident enough to support their children's digital activities, especially when these had to do with the students' homework [26]. Some researchers also expecte that fathers would do that more than mothers, given that fathers usually have more experience with computer technology [27], [28]. Interesting to note is the fact that using the Internet for learning purposes (such as preparing homework, learning Internet skills, and downloading software) is probably related not only to the quantity of time that parents and children spend together, but also to the extent that the child is feeling close to parents [29].

Becoming competent in mathematics can be conceived of as acquiring a mathematical disposition (see, for example, [34], [35]). Traditionally the dominant form of learning in schools has been teacher-directed learning or guided learning: "a trainer or teacher takes all the relevant decisions and the learner can and should follow him or her. He decides about the goals of learning, the learning strategies, the way to measure outcomes and he takes care of feedback, judgments, and rewards" [36]. Besides guided learning, in [36] the authors distinguish two other ways of learning: experiential and action learning. To facilitate and support learners through the gradual and progressive acquisition of adaptive mathematical competence, novel classroom practices and cultures are needed. These practices and cultures should create the conditions for a substantial shift from guided learning toward experiential as well as action learning, resulting in a balanced and integrated use of the three ways of learning: constructive, self-regulated, and contextual or situated [37].

The constructivist view of learning has become common ground among educational psychologists (see, for example, [36], [38], [39]). Constructivism implies that constructive learning is self-regulated. According to [40], self-regulation 
"refers to the degree that individuals are metacognitively, motivationally, and behaviorally active participants in their own learning process". According to [37] "constructive and selfregulated learning processes should preferably happen and be studied in context", and because learning is collaborative, the learning efforts are distributed over the individual student, its partners in the learning environment, and the (technological) resources and tools that are available [41].

The available literature provides substantial evidence supporting the positive effects of collaborative learning [41]-[43]; this does not means that students stop to try to achieve and also develop new knowledge individually.

As stated by [44] "starting as much as possible from tasks and problems that are meaningful and challenging for students, learning environments should initiate socially supported constructive learning processes that enhance students's cognitive and volitional self-regulatory skills". It is expected that students will be able to use their acquired knowledge and skills to solve mathematics-related situation and problems in everyday life, something that [45], [46] call preparation for future learning.

\section{THE SYSTEM}

There is a huge number of computer applications and Internet resources that can be used as education tools in the teaching of virtually everything, including chemistry, physics, engineering, medicine, mechanics, to name only a few. For example, in [26] the authors proposed a set of collaborative learning activities via interactive video-conferencing in elementary/primary schools to test parents' attitudes towards ITbased learning. In [47] the authors developed a web-based system to promote teacher-parent-student communication through Internet, and in [48] it is presented an algorithm for automatic checking of exercises in a dynamic geometry system, which has been developed considering the computational restrictions (computers that have low-processing capabilities) and that can be used without restrictions with any other learning management system.

As usually happens in Portugal, the lack of tools supporting the authoring and automatic checking of exercises for specific topics in primary education (e.g., ordering and numbering in mathematics) drastically reduces the advantages in the use of e-learning environments on a larger scale. As noted before, the system that we propose here aims at reduce this lack.

The system has two main components: back-office, and front-end. In short, the back-office works as the administration component of the system, and the front-end is the system's visibility. The programming language used to develop the back-office was PHP, to the front-end was ActionScript (AS2), and the databases were constructed using MySQL. Figure 1 shows a system's global layer organization; at the bottom we have the data management layer (managing the data from the users, exercises, etc.), the second layer is the functional layer, i.e., the one responsible for the relations between the exercises, templates, homeworks, and at the top we have the statistics layer, where the information is returned (presented) to the

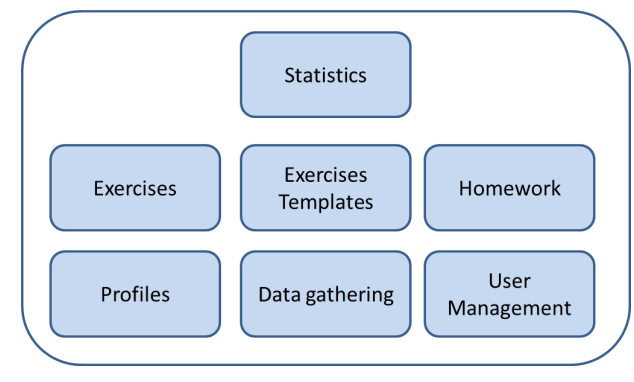

Fig. 1. System global layer organization.

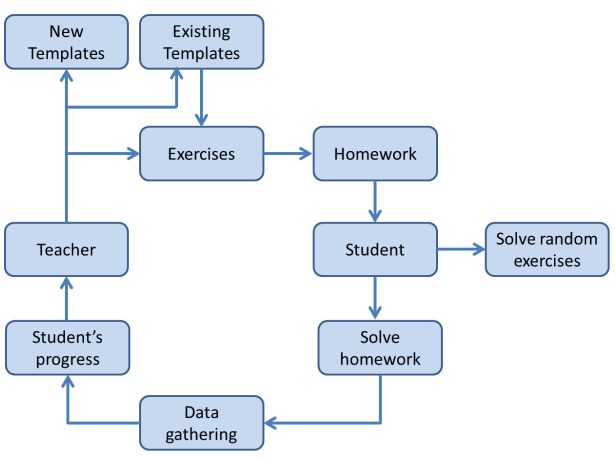

Fig. 2. Main relations between teachers and students and what they can do.

users (i.e., the teachers/educators). In figure 2 we can see the main relations between teachers and students and what they can do. As we can see, a teacher may create new templates or edit exiting templates; from the existing templates s/he can create the exercises. Then, from a list of existing exercises the teacher creates homeworks. On the other side, a student can solve the homework recommended by the teacher. It is from the set of homeworks solved by the students that data is gathered to be statistically processed and presented to the teacher. Obviously, the teacher creates new sets of homework based on these data, but more importantly, based on all the other data s/he collects during classes/lectures. In the next subsections we will return to this in more detail.

The user of this system must be registered, and in order to get full system's features and advantages s/he must pass through the authentication (login and password) process.

A non-registered user may do random exercises but s/he has no access to homework, statistics, and new exercises areas. A registered student has access to its own personal area, where $\mathrm{s} /$ he can see (and do) the homework recommend by its teacher.

The registered teacher may post new exercises, recommend students' homework, and statistics. The statistics module grabs all the information of every student. The teacher may query information from a student (individually), a group of students or the entire class. This information includes grades, time spent per exercise, number of tries, who has done the homework (complete homework or the exercises individually), among other.

Note that a subset of exercises of the Internet-based collaborative system presented here was successfully applied to 


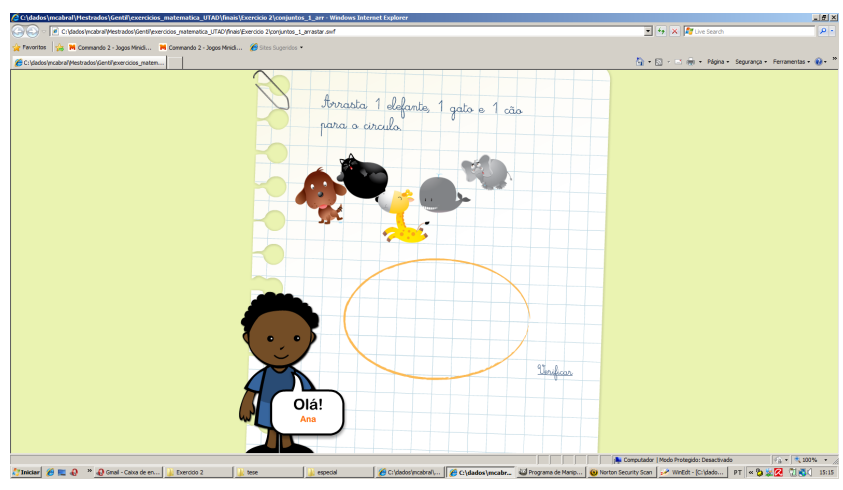

(a)

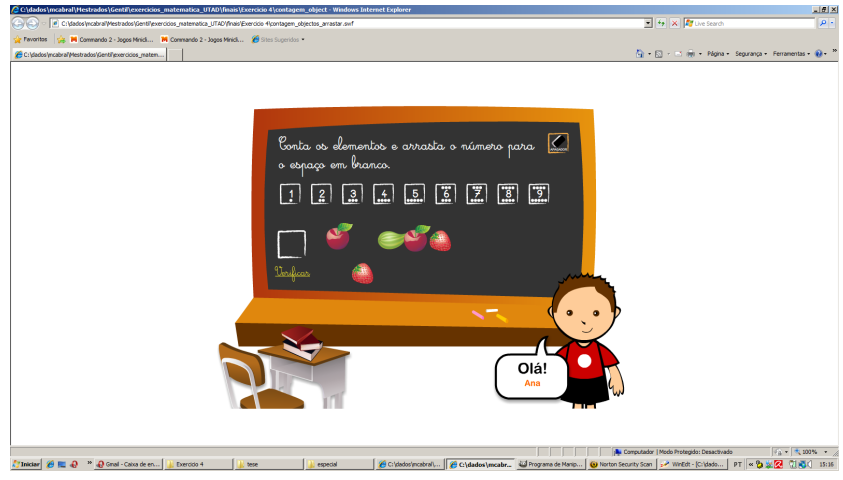

(b)

Fig. 3. Sample exercises.

children with special education needs, as reported in [49].

\section{A. Posting of new exercises}

New exercises are posted based on the existing templates. New templates may also be posted by teachers having programming skills. It is based on the template's flexibility that a new exercise is customized; that is, we may have a template where the only thing that can be changed is the exercise text, or a template where everything, including the characters, objects (fruits, animals, etc.), text (color, font/shape/size, etc.), images, video, etc., can be included or changed/customized. If a teacher, that does not have the programming skills, needs a new template, s/he may post the corresponding message in the forum area of the system (collaborative work).

For a given (existing) template, the user (teacher) must introduce all the need fields. In the example shown in figure 3(a), the student is asked to drag an elephant, a cat and a dog into the circle. This exercise was built based on a template requiring the following fields: exercise wording, the text that a student actually sees and read; list of possibilities, selected from different sets of animals, fruits, plants, etc., figures; solution list, i.e., the solution. All other components are static (cannot be changed). In the example shown in figure 3(b), the student is asked to count the number of elements and drag the corresponding number into the blank space. In this case the teacher is asked to fill in the exercise wording, the list of objects (fruits in this case) and the solution (the number of objects).

As you can see the character in these templates "says" Olá! Ana (Hello! Ana), but obviously this information was retrieved from the user login name and was not provided by the teacher that posted the exercise (for posting proposes, this is considered static information).

The teacher can always change an exercise, by editing it, or even delete an exercise, and list the existing exercises (all, by category, template, etc.).

\section{B. Students}

In the exercises area the user (student) may choose to do his/her homework or randomly chosen exercises. Only the exercises belonging to a homework set will be used to extract statistical data (because these data will be transformed into information only by a teacher). Nevertheless, all the tried exercises give automatic feedback to the student about its correctness, by clicking the verify (Verificar) button.

\section{Teachers}

Besides de capability to post new exercises and templates, in the teachers' area it is possible to produce the different sets (lists) of homework exercises, and access the statistical data.

To produce a homework list, the teacher simple choose the exercises from the existing ones, and then the group of students who should apply to the list. A teacher can have the groups of students s/he wants by just creating emailing lists (e.g., for the different classes, and groups in a class).

Statistical data is "attached" to a particular list. The teacher may also concatenate statistical data from several groups. This may be very helpful if the class needs to be divided into several groups (e.g., due its heterogeneity). The data can be either presented as tables and as plots. Also included in the statistical data are the "observation index" and "assessment method", as proposed in [47].

\section{Forum/discussion}

This area of the system is intended to promote the interaction between teachers, parents and students. We believe that this area in particular may be used to increment the use of IT by teachers and students, but also to promote teacher-studentparent communication, especially if both teachers, students, and parents will share their thoughts, worries, activities, strategies, etc., and thus allowing for a collaborative work through this system.

To this end, both teachers, students and parents/carers can post and e-mail questions/opinions to other participants in the discussion/forum area, including text message, photos, audio and video, in order to foster rich contexts for discussion. This process of discussion is divided into three steps: first, prepare the question/opinion (e.g., write the question/opinion on a paper and then take a picture of it or record the question in sound or video); second, send the multimedia message by e-mail (individual e-mail accounts are set for each participant); third, the system analyzes the message and publishes it in the discussion community (the e-mail's subject line becomes the 
topic title of the discussion and the e-mail's body is the body of the discussion).

\section{Discussion}

Technology has profoundly changed the way we learn and live. This relationship appears to be quite complex, in that IT, and especially socially- and technologically-rich learning environments, seems to both require and foster skills and learning.

In the view of several authors it seems that we are moving to a "digital learning" (e.g., [50]-[55]). According to [51] there are five factors that favor de use of the Internet in education: its social acceptance, it facilitates a sense of control and therefore ownership for educators far more than previous technologies, the web browser has become a generic interface, it is both an interactive (do something with the information rather than just being a passive recipient) and personal (all learners are not the same) medium, is a sustaining (e.g., a retailer that uses it to supplement its physical shops, for instance by home delivery from supermarkets) and disruptive (e.g., it does not intend web based shopping to displace its standard retail outlets, but rather it hopes the two will complement each other, and thus altering the organization in which it is implemented) technology.

Internet can be used to supplement face-to-face teaching; for example, many campus based universities use the Internet not to replace their traditional face-to-face mode of delivery, but rather as a means of supplementing it (e.g., web pages can be used to provide additional information, or e-mail be used as a means of contacting tutors of large courses). Of course that there are topics that better suit its use (a "Introduction to Information Technology" course, and a course for teachers wanting to learn about computer conferencing, are examples of courses were using the technology effectively forms an integral part of the academic content of the course) without forget pedagogic suitability (for example, the resource based learning, where students can be presented with a wide range of resources, often external to the university, were students derive their own learning experience from these resources within the overall framework of the course). Internet's usage also leads to institutional benefit because institutions can benefit from the use of Internet in education, both on campus and in reaching new audiences, and from the fact that it can be seen as a Computer Assisted Learning delivery mechanism-many courses are using Internet to deliver simulations, visualization aids and interactive tools.

Additionally, mathematics is a fundamental human activity, a way of making sense of the world. Children possess a natural curiosity and interest in mathematics, and come to school with an understanding of mathematical concepts and problem-solving strategies that they have discovered through explorations of the environment that surrounds them. According to [56] and [57], primary education is an important time of transitional growth in students' mathematical thinking. In order to become more accurate in their work, both in reading problems and in working out solutions, primary students need more practice to reinforce what they are learning, a process which traditionally takes place on paper. In general, after students have completed practice exercises or homework, very often they have to wait for their teacher to check it and provide feedback. These interruptions can reduce students' interest in learning as well as learning efficiency.

The research of [57] shows that mathematically literate students think flexibly about how to best solve a problem. Even so, most approaches that even mathematically literate students adopt are distributed in textbooks or tutoring books. Unfortunately, these materials are usually designed for average learners, and it is often difficult to find the best-fitting content for students with differing abilities. For example, in Portugal all the classes have only one textbook designed for all students, but literate students may need a higher-level tutoring, and illiterate may need a lower-level tutoring. Therefore, the depth and flexibility of ability gained from these textbooks are restricted. Some programs based on e-learning technology may provide personalized contents for learners by collecting the learning process. But primary students may become restless and unfocused when staying in front of computers for learning mathematics (or other subjects) during long periods of time.

Teachers, but also parents and carers, have an important word to say in this process; as noted in [53], "the teacher must be centrally involved, actively instructing and mentoring students, especially at the initial stages of work on a project. Unfocused instruction can leave students rudderless, and this is particularly harmful to at-risk students, such as those with learning disabilities, limited literacy, and language skills, or insufficient background knowledge"; and according to [58] "Parents have a vital role to play as prime educators of young children and some children will have many achievements at home using ICT that can be celebrated and built on. Young children and their families may access learning available in the community, for instance community networks, libraries and learning centres, well before entry to early years establishments. Some parents will have developed ICT skills and knowledge that can usefully be shared with the early years setting."

But, as already noted in [9] in a research project developed in UK, "More importantly, there was no extra time available for the staff involved to spend on exploring and using the communications network. It was an additional burden in an already crowded professional agenda.". Likewise, in Portugal we do not expect that teachers have any extra time to explore some novel methodology without the existence of any obvious advantages.

One such obvious advantage of the system here proposed is time saving. In Portugal, most of the times, the teacher writes in the exercise-book of each pupil (at least in the blackboard) the set of homework exercises that s/he should try to solve. This is a handy work, and consequently very time consuming. When students return with their homework, the teacher must read and correct, one-by-one, every exercise-book, in order to have and give feedback to the students. The teacher should also analyze each student's work, in order to evaluate the student's progress and potentially introduce some programme and/or 
pedagogical adjustments. Obviously, this analysis should also be made to the global class.

With the system presented here the teacher can select different sets of exercises for each student or, alternatively, propose the same set of exercises to the whole class, and this simply by creating e-mail lists. The system will then provide the teacher with statistical data concerning each student and the entire class. We believe that these data will greatly help the teacher in evaluating his/her work, and help with the mentioned adjustments. The selection of different exercises sets may not directly lead to a time reduction of the teacher's work, but its automatic check and the statistical data do. We believe that teachers can use this extra time to better understand were and why some children are having troubles.

This system also invites the community to share ideas and experiences among them through the participation in collaborative discussion. As explained in section III-D, both teachers, students and parents can e-mail questions to other participants in the discussion, including text message, photos, audio and video, in order to foster rich contexts for discussion.

We want that in the near future the tool presented here may be used in English-speaking countries, since the only thing that needs to be changed is the interface. From the exercises point of view, they do not need adjustments, because it all depends on the templates (the templates must be designed in English, as well as everything they contain, such as video, images, text, speech, music, etc.). The system itself was developed in a multilingual platform.

\section{CONCLUSiOnS}

From the teacher point-of-view, we believe that the biggest advantages of the system here proposed is time saving, but also the gathered statistical data concerning the different groups of students that the teacher elected. From these data on, the teacher easily sees where the students are having problems and decide what to do next.

From the student point-of-view, the prompt feedback about the exercises correctness, added to the training with different exercises sets about the same subject, besides the utilization of video, color, sound, etc., that positively reinforce the different child's senses, are elected as the main advantages.

In the view of [53], "New technologies do not replace the need for strong human mentorship, but, indeed, amplify the role of such mentorship". We believe that the proposed system will enable students, parents and teachers to become active components of an interactive learning strategy plan [59], [60]. Obviously, students must become into contact with the new teaching/studding tools progressively, in order to become a part of the learning environment as smoothly as possible.

As mentioned before, we are ware of the paramount role that parents have in the participation of their children's education. It is very important that the parents (relatives and tutors) actively participate in the scholar life of their children, and in particular in their homework. Accompanying a student's homework helps a parent to support is child, to stay aware of what is going on in the school, and also to get involved in the scholar community. Here we are talking about a virtual community that can share their opinions through a discussion forum, but most important, through the posting of exercises that their own children can do. In our opinion, this is very important and gets reinforced by the fact that most parents are also teachers; who better than parents knows what is needed by their children? Note that, as [30] states, "it remains an open question as to whether schools are so dramatically different in what they teach in comparison to informal learning environments in the ambient culture and whether informal learning and schooling interact with more intuitive folk systems in different ways".

\section{REFERENCES}

[1] G. M. M. C. Santos and M. J. C. S. Reis, "Formação de professores de Trás-os-Montes e Alto Douro na utilização da internet-1a fase SCETAD-AEP," in II Conferência Internacional de Tecnologias de Informaç ao e Comunicaç ao na Educaç ao-Challenges 2001, Braga, Portugal, 2001, pp. 861-871.

[2] M. Reis, G. Santos, C. Teixeira, N. Vieira, and S. Carvalho, "Internet as a learning tool in the 'Trás-os-Montes e Alto Douro' region," in International Conference on ICT's in Education, Junta de Extremadura, Consejería de Educación, Ciencia y Tecnología, Sociedad de la Información, Badajoz, Spain, 2002, pp. 1494-1498.

[3] M. Reis and G. Santos, "Internet in the elementary schools of "Trásos-Montes e Alto Douro" region - part two: the method," in IADIS International Conference (e-Society 2003), Lisbon, Portugal, 2003, p. 1040.

[4] N. Pratt, "Multi-point e-conferencing with initial teacher training students in England: Pitfalls and potential," Teaching and Teacher Education, vol. 24, no. 6, pp. 1476-1486, Aug. 2008.

[5] M. J. C. S. Reis, G. M. M. C. Santos, and P. J. S. G. Ferreira, "Promoting the educative use of the internet in the Portuguese primary schools: a case study," Aslib Proceedings, vol. 60, no. 2, pp. 111-129, 2008.

[6] K. S. Brown, L. A. Welsh, K. H. Hill, and J. P. Cipko, "The efficacy of embedding special education instruction in teacher preparation programs in the United States," Teaching and Teacher Education, vol. 24, no. 8, pp. 2087-2094, Nov. 2008.

[7] H. T. Gil and F. de Vasconcelos, "e-learning as a "Magical" way to teach and learn in a modern world?!" in 2nd International Conference on E-Learning, Proceedings, Remenyi, D, Ed. Curtis Farm, Kidmore End, Nr Reading, RG4 9AY, England: Academic Conferences Ltd, 2007, pp. 173-178, 2nd International Conference on e-Learning (ICEL 2007), New York, NY, JUN 28-29, 2007.

[8] J. Wishart, "Internet safety in emerging educational contexts," Computers \& Education, vol. 43, no. 1-2, pp. 193-204, August-September 2004.

[9] D. Watson, B. Blakeley, and C. Abbott, "Researching the use of communication technologies in teacher education," Computers \& Education, vol. 30, no. 1/2, pp. 15-21, 1998.

[10] A. Hargeaves, "Foreword," in The lives of teachers, M. Huberman, Ed. Columbia University, DC: Teachers College Press, 1993, pp. vii-ix.

[11] M. Lampert and D. L. Ball, Teaching, multimedia and mathematics. New York: Teachers College Press, 1998.

[12] S. J. Pijlc and C. J. Meijer, "Factors in inclusion: A framework," in Inclusive education: A global agenda, S. J. Pijl, C. J. W. Meijer, and S. Hegarty, Eds. London, UK: Routledge, 1997, pp. 8-13.

[13] N. Selwyn and K. Bullon, "Primary school children's use of ICT," British Journal of Educational Technology, vol. 31, no. 4, pp. 321-332, Oct. 2000.

[14] E. M. Rogers, Diffusion of innovations, 3rd ed. New York: Macmillan Publishing Company, Inc., 1983.

[15] B. A. Corbett and J. D. Willms, "Information and communication technology: Access and use," Education Quarterly Review, vol. 8, no. 4, 2002.

[16] K. Facer, J. Furlong, R. Furlong, and R. Sutherland, Screen play: Children and computing in the home. London and New York: Routledge Falmer, 2003.

[17] S. Williams and S. Ogletree, "Preschool children's computer interrest and competence," Early Childhood Research Quarterly, vol. 7, pp. 209224, 1992 
[18] R. E. Kraut, M. L. Patterson, V. Ludmark, S. Kiesler, T. Muklopadhyay, and W. Scherlis, "Internet paradox: A social technology that reduces social involvement and psychological well being?" American Psychologist, vol. 53, pp. 1017-1032, 1998.

[19] A. Lenhart, L. Raine, and O. Lewis, "Teenage life online: The rise of the instant-message generation and the Internet's impact on friendships and family relationships," Pew and American Life Project, Washington, DC, Tech. Rep., 2001. [Online]. Available: http://www.pewinternet.org/pdfs/PIP_Teens_Report.pdf

[20] K. Subrahmanyam, P. Greenfield, R. Kraut, and E. Gross, "The impact of computer use on children's and adolescents' development," Applied Developmental Psychology, vol. 22, pp. 7-30, 2001.

[21] G. Valentine and S. Holloway, "On-line dangers? geographies of parents' fears for children's safety in cyberspace," Professional Geographer, vol. 53, pp. 71-83, 2001.

[22] J. M. Graham and R. S. Banks, "Young children's initial exploration of computers," 2000. [Online]. Available: http://ceep.crc.uiuc.edu/pubs/ katzsym/graham.html

[23] M. Sothern, "Obesity prevention in children: Physical activity and nutrition," Nutrition, vol. 20, pp. 704-708, 2004.

[24] Eurobarometer, "Illegal and harmful content on the internet," European Opinion Research Group EEIG, Tech. Rep., 2004 [Online]. Available: http://ec.europa.eu/information_society/activities/ sip/docs/eurobarometer/eurobarometer_2003_15_ms.pdf

[25] L. Plowman and C. Stephen, "Children, play, and computers in preschool education," British Journal of Educational Technology, vol. 36, no. 2, pp. 145-157, 2005.

[26] P. S. Anastasiades, E. Vitalaki, and N. Gertzakis, "Collaborative learning activities at a distance via interactive videoconferencing in elementary schools: Parents' attitudes," Computers \& Education, vol. 50, no. 4, pp. 1527-1539, May 2008.

[27] M. Pettersson and I. Carlsson, "Perspectives on digital divide-Internet usage and attitudes in Arusha, Tanzania. A minor field study," 2004. [Online]. Available: http://ceep.crc.uiuc.edu/pubs/katzsym/graham.html

[28] R. Wang, S. M. Bianchi, and S. B. Raley, "Teenagers' internet use and family rules: A research note," Journal of Marriage and Family, vol. 67, no. 5, p. 1249, 2005.

[29] G. S. Mesch, "The family and the internet: The Israeli case," Social Science Quarterly, vol. 84, no. 4, p. 1038, 2003.

[30] F. C. Keil, "Adapted minds and evolved schools," Educational Psychologist, vol. 43, no. 4, pp. 196-202, 2008.

[31] L. S. Vygotsky, Mind in society: Development of Higher Psychological Processes, M. Cole, V. John-Steiner, S. Scribner, and E. Souberman, Eds. Harvard University Press, 1978.

[32] J. V. Wertsch, "The voice of rationality in a sociocultural approach to mind," in Vygostky and education: Instructional implications and applications of sociohistorical psychology, L. C. Moll, Ed. New York, NY: Cambridge University Press, 1992, pp. 111-126.

[33] S. M. Papert, Mindstorms: Children, Computers, and Powerful Ideas. New York: Basic Books, 1980.

[34] E. D. Corte and L. Verschaffel, "Mathematical thinking and learning," in Handbook of child psychology, 6th ed., K. A. Renninger, I. E. Sigel, W. Damon, and R. M. Lerner, Eds. Hoboken, NJ: John Wiley \& Sons, 2006, vol. 4: Child psychology and practice, pp. 103-152.

[35] N. R. Council, "Adding it up: Helping children learn mathematics," in Mathematics Learning Study Committee, Center for Education, Division of Behavioral and Social Sciences and Education, J. Kilpatrick, J. Swafford, and B. Findell, Eds. Washington, DC: National Academy Press, 2001.

[36] R. J. Simons, J. van der Linden, and T. Duffy, "New learning: Three ways to learn in a new balance," in New learning, R. J. Simons, J. van der Linden, and T. Duffy, Eds. Dordrecht, The Netherlands: Kluwer Academic Publishers, 2000, pp. 1-20.

[37] E. D. Corte, "Learning from instruction: the case of mathematics," Learning Inquiry, vol. 1, pp. 19-30, 2007.

[38] D. C. Phillips, Ed., Constructivism in education: Opinions and second opinions on controversial issues. Ninety-ninth yearbook of the national Society for the Study of Education. Part I. Chicago, IL: National Society for the Study of Education, 2000.

[39] L. P. Steffe and J. Gale, Eds., Constructivism in education. Hillsdale, NJ: Lawrence Erlbaum Associates, 1995.

[40] B. J. Zimmerman, "Dimensions of academic self-regulation: A conceptual framework for education," in Self-regulation of learning and performance: Issues and educational applications, D. H. Schunk and
B. J. Zimmerman, Eds. Hillsdale, NJ: Lawrence Erlbaum Associates, 1994, pp. 3-21.

[41] G. Salomon, Ed., Distributed cognition. Psychological and educational considerations. Cambridge, UK: Cambridge University Press, 1993.

[42] E. Lehtinen, "Computer-supported collaborative learning: An approach to powerful learning environments," in Powerful learning environments: Unravelling basic components and dimensions. Advances in Learning and Instruction Series, E. D. Corte, L. Verschaffel, N. Entwistle, and J. van Merriënboer, Eds. Oxford, UK: Elsevier Science Ltd, 2003, pp. 35-53.

[43] J. van der Linden, G. Erkens, H. Schmidt, and P. Renshaw, "Collaborative learning," in New learning, R. Simons, J. van der Linden, and T. Duffy, Eds. Dordrecht, The Netherlands: Kluwer Academic Publishers, 2000, pp. 37-54.

[44] E. D. Corte, "Mainstreams and perspectives in research on (mathematics) learning from instruction," Applied Psychology: An International Review, vol. 53, pp. 279-310, 2004.

[45] J. D. Bransford and D. L. Schwartz, "Rethinking transfer: A simple proposal with multiple implications," in Review of research in education, A. Iran-Nejad and P. Pearson, Eds. Washington, DC: American Educational Research Association, 1999, vol. 24, pp. 61-100.

[46] J. D. Bransford, R. Stevens, D. Schwartz, A. Meltzoff, R. Pea, J. Roschelle, N. Vye, P. Kuhl, P. Bell, B. Barron, B. Reeves, and N. Sabelli, "Learning theories and education: Toward a decade of synergy," in Handbook of educational psychology, 2nd ed., P. A. Alexander and P. H. Winne, Eds. Mahwah, NJ: Lawrence Erlbaum Associates, 2006, pp. 209-244.

[47] H.-m. Chen, C. Yu, and C.-s. Chang, "E-Homebook system: A webbased interactive education interface," Computers \& Education, vol. 49, no. 2, pp. 160-175, Sep. 2007.

[48] S. Isotani and L. d. O. Brandao, "An algorithm for automatic checking of exercises in a dynamic geometry system: iGeom," Computers \& Education, vol. 51, no. 3, pp. 1283-1303, Nov. 2008.

[49] M. Reis, L. Cabral, E. Peres, M. Bessa, A. Valente, R. Morais, S. Soares, J. Baptista, A. Aires, J. Escola, J. Bulas-Cruz, and M. Reis, "Using information technology based exercises in primary mathematics teaching of children with cerebral palsy and mental retardation: A case study," TOJET: The Turkish Online Journal of Educational Technology, vol. 9, no. 3, pp. 106-118, July 2010.

[50] E. M. Rogers, Diffusion of innovations, 4th ed. New York: Kindle Edition, 1995.

[51] M. Weller, Delivering Learning on the Net: the why, what \& how of online education. London and New York: RoutledgeFalmer, Taylor \& Francis Group, 2002.

[52] T. S. Roberts, Computer-Supported Collaborative Learning in Higher Education. London, UK: Idea Group Publishing Inc., 2005.

[53] M. Warschauer, "The paradoxical future of digital learning," Learning Inquiry, vol. 1, pp. 41-49, 2007.

[54] G. Bull and T. Hammond, "The future of E-Learning in schools," in Handbook on Information Technologies for Education and Training, 2nd ed., H. H. Adelsberger, Kinshuk, J. M. Pawlowski, and D. Sampson, Eds. Springer-Verlag Heidelberg, 2008, pp. 345-361.

[55] T. Willoughby and E. Wood, Eds., Children's Learning in a Digital World. 350 Main Street, Malden, MA 02148-5020, USA: Blackwell Publishing Ltd, 2008.

[56] J. Johnson, "Teaching and learning mathematics: Using research to shift from the "yesterday" mind to the "tomorrow" mind," State Superintendent of Public Instruction, Washington, Tech. Rep., 2004. [Online]. Available: http://www.k12.wa.us/research/pubdocs/pdf/ mathbook.pd

[57] Expert Panel on Mathematics, "Teaching and learning mathematics," The Report of the Expert Panel on Mathematics in Grades 4 to 6 in Ontario, Toronto, Canada: Ontario Ministry of Education, Tech. Rep., 2004. [Online]. Available: http://www.edu.gov.on.ca/eng/ document/reports/numeracy/panel/numeracy.pdf

[58] Scottish Executive, "Early learning, forward thinking: The policy framework for ict in early years," Learning and Teaching Scotland, Scottish Executive, Tech. Rep., 2003. [Online]. Available: http: //www.ltscotland.org.uk/Images/ict_framework_tcm4-122121.pdf

[59] P. A. Kirschner, "Learning in innovative learning environments," Computers in Human Behavior, vol. 21, no. 4, pp. 547-554, 2005.

[60] B. S. Woodard, "Technology and the constructivist learning environment: Implications for teaching information literacy skills," Research Strategies, vol. 19, no. 3-4, pp. 181-192, 2003. 